\title{
Uso de mini-implantes para mesialização de molares inferiores na má oclusão de
}

\section{Classe II: relato de caso}

\author{
Use of mini-implants for mesialization of mandibular molars in Class II malocclusion: case report \\ Uso de miniimplantes para mesialización de molares mandibulares en maloclusión Clase II: reporte
}

de caso

Recebido: 30/06/2021 | Revisado: 06/07/2021 | Aceito: 05/08/2021 | Publicado: 09/08/2021

\author{
Luis Henrique Braga Sader \\ ORCID: https://orcid.org/0000-0002-0776-421X \\ Centro Universitário Ingá Uningá, Brasil \\ E-mail: luishenrique.sader@gmail.com \\ Augusto Cesar Rodrigues de Souza \\ ORCID: https://orcid.org/0000-0001-5590-3045 \\ Instituto Odontológico de Pós-Graduação IOPG, Brasil \\ E-mail: augustocrs@hotmail.com \\ Angela Thais Shibata Santos \\ ORCID: https://orcid.org/0000-0002-1007-5730 \\ Instituto Catarinense de Odontologia e Saúde, Brasil \\ E-mail: angelashibatasantos@gmail.com \\ Paula Cotrin \\ ORCID: https://orcid.org/0000-0002-6230-0522 \\ Centro Universitário Ingá Uningá, Brasil \\ E-mail: cotrin@ hotmail.com \\ Karina Maria Salvatore de Freitas \\ ORCID: https://orcid.org/0000-0001-9145-6334 \\ Centro Universitário Ingá Uningá, Maringá, Brasil \\ E-mail:kmsf@uol.com.br \\ Fabrício Pinelli Valarelli \\ ORCID: https://orcid.org/0000-0002-4285-486X \\ Centro Universitário Ingá Uningá, Brasil \\ E-mail: fabriciovalarelli@gmail.com
}

\begin{abstract}
Resumo
Pacientes adultos apresentam com determinada frequência a ausência dos primeiros molares inferiores, e a reabilitação destes espaços se faz necessárias sendo de forma protética ou com o fechamento ortodôntico. Este caso clínico traz uma paciente que apresenta má oclusão classe II e apinhamentos superiores concomitante à ausência dos primeiros molares inferiores. Foi decidido realizar o tratamento com extrações dos primeiros pré-molares superiores e mesialização por meio de ancoragem em mini-implantes dos segundos molares inferiores para o fechamento dos espaços das perdas dos primeiros molares inferiores. Os resultados foram bastante satisfatórios. A movimentação ortodôntica não causou efeitos colaterais significativos e os mini-implantes tiveram um papel fundamental para que não houvesse alteração no perfil da paciente. Conclui-se que a ancoragem em mini-implantes pode ser efetiva para a mesialização dos molares inferiores com mínimos efeitos no periodonto e no perfil.
\end{abstract}

Palavras-chave: Dentes molares; Ancoragem ortodôntica; Parafusos ósseos.

\begin{abstract}
Adult patients frequently present the absence of mandibular first molars, and the rehabilitation of these spaces is necessary, whether prosthetically or with orthodontic closure. This clinical case reports a patient who presents Class II malocclusion and maxillary crowding concomitant with the absence of mandibular first molars. It was decided to carry out the treatment with extractions of the maxillary first premolars and mesialization through mini-implant anchorage of the mandibular second molars to close the spaces of loss of the mandibular first molars. The results were quite satisfactory. The orthodontic movement did not cause significant side effects, and mini-implants played a fundamental role in preventing a change in the patient's profile. It is concluded that mini-implant anchorage can be effective for the mesialization of mandibular molars with minimal effects on the periodontium and profile.
\end{abstract}

Keywords: Molar teeth; Orthodontic anchorage; Bone screws.

\section{Resumen}

Los pacientes adultos presentan frecuentemente la ausencia de primeros molares inferiores, siendo necesaria la rehabilitación de estos espacios, ya sea protésicamente o con cierre ortodóncico. Este caso clínico presenta un 
paciente que presenta maloclusión clase II y apiñamiento superior concomitante con ausencia de primeros molares inferiores. Se decidió realizar el tratamiento con extracciones de los primeros premolares superiores y mesialización mediante miniimplante de anclaje de los segundos molares inferiores para cerrar los espacios de pérdida de los primeros molares mandibulares. Los resultados fueron bastante satisfactorios. El movimiento de ortodoncia no provocó efectos secundarios importantes y los miniimplantes jugaron un papel fundamental en la prevención de cambios en el perfil del paciente. Se concluye que el anclaje de miniimplantes puede ser eficaz para la mesialización de molares mandibulares con efectos mínimos sobre el periodonto y el perfil.

Palabras clave: Molares; Anclaje ortodóntico; Tornillos óseos.

\section{Introdução}

Atualmente a frequência de realização de tratamento ortodôntico em indivíduos adultos é maior. Entre as principais queixas a serem tratadas estão a reabilitação dos espaços edêntulos dos primeiros molares permanentes. A reabilitação desses espaços tem como objetivo devolver a função mastigatória recuperando o equilíbrio funcional e estético (Araújo, Nascimento, Bezerra, \& Sobral, 2006; Carano, Velo, Incorvati, \& Poggio, 2004). A perda dos primeiros molares inferiores causa alterações desfavoráveis na cavidade bucal: inclinações e angulações dentárias, resultando estas em traumas oclusais e possíveis problemas periodontais (Sakima et al., 1999). Assim, as reabilitações podem ser realizadas através de implantes dentários ou através da utilização de aparelhos ortodônticos com a finalidade de mesializar os dentes posteriores para o espaço edêntulo. A utilização de mini-implantes para obtenção de ancoragem absoluta com objetivo de fechamento de espaços dos primeiros molares ausentes, evitando a retração da bateria anterior e não prejudicando o perfil facial do paciente é uma opção de tratamento aceitável que favorece o resultado esperado e conforto para o paciente durante o tratamento (Carano et al., 2004; Park, Jeong, \& Kwon, 2006).

A mesialização dos dentes posteriores visando o fechamento dos espaços presentes deixados pela perda dos primeiros molares inferiores deve ser realizada através de movimento de corpo, assim favorecendo o resultado final do tratamento (Roberts, Marshall, \& Mozsary, 1990). A mecânica ortodôntica quando empregada bilateralmente é sempre mais favorável, ao passo que nos casos de perdas dentárias unilaterais, a mecânica assimétrica deve ser muito bem controlada para não gerar efeitos colaterais que dificultem a finalização da correção e o sucesso do tratamento (Valarelli et al., 2014).

O presente trabalho tem como objetivo demonstrar através de relato de caso clinico, aspectos relacionados ao fechamento de espaços dos primeiros molares inferiores ausentes, bilateralmente, através da mesialização dos dentes posteriores, ancorados em mini-implantes, sem causar efeitos indesejáveis nos dentes adjacentes e no perfil facial do paciente.

\section{Relato do Caso Clínico}

Paciente D.M.C.S, 35 anos, apresentou-se na clínica ortodôntica para o exame inicial queixando-se de má oclusão, dentes apinhados e espaços edêntulos na região dos molares inferiores. A ausência dentária dificultava a mastigação segundo o relato da paciente.

A análise extrabucal no início do tratamento demonstrou padrão equilibrado da face com selamento labial passivo, boa exposição dos incisivos superior no sorriso, linha média dentária superior coincidente com o plano sagital mediano, perfil facial suavemente convexo com ângulo nasolabial normal (Figura 1). 
Figura 1 - Análise extrabucal ao início do tratamento.

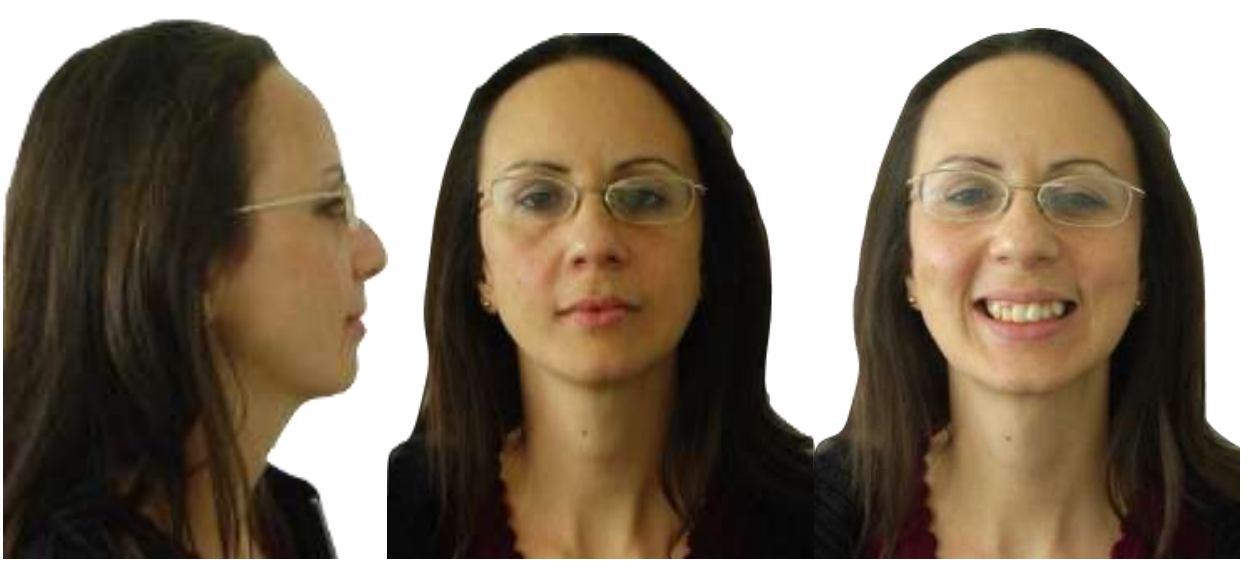

Fonte: Autores.

A análise intrabucal demonstrou má oclusão de Classe II completa no lado esquerdo, 1/2 Classe II no lado direito, apinhamentos dentários no arco superior e inferior, primeiro pré-molar inferior direito sem porção coronária e espaços edêntulos na região dos primeiros molares inferiores (Figura 2).

Figura 2 - Aspectos intrabucais ao início do tratamento.

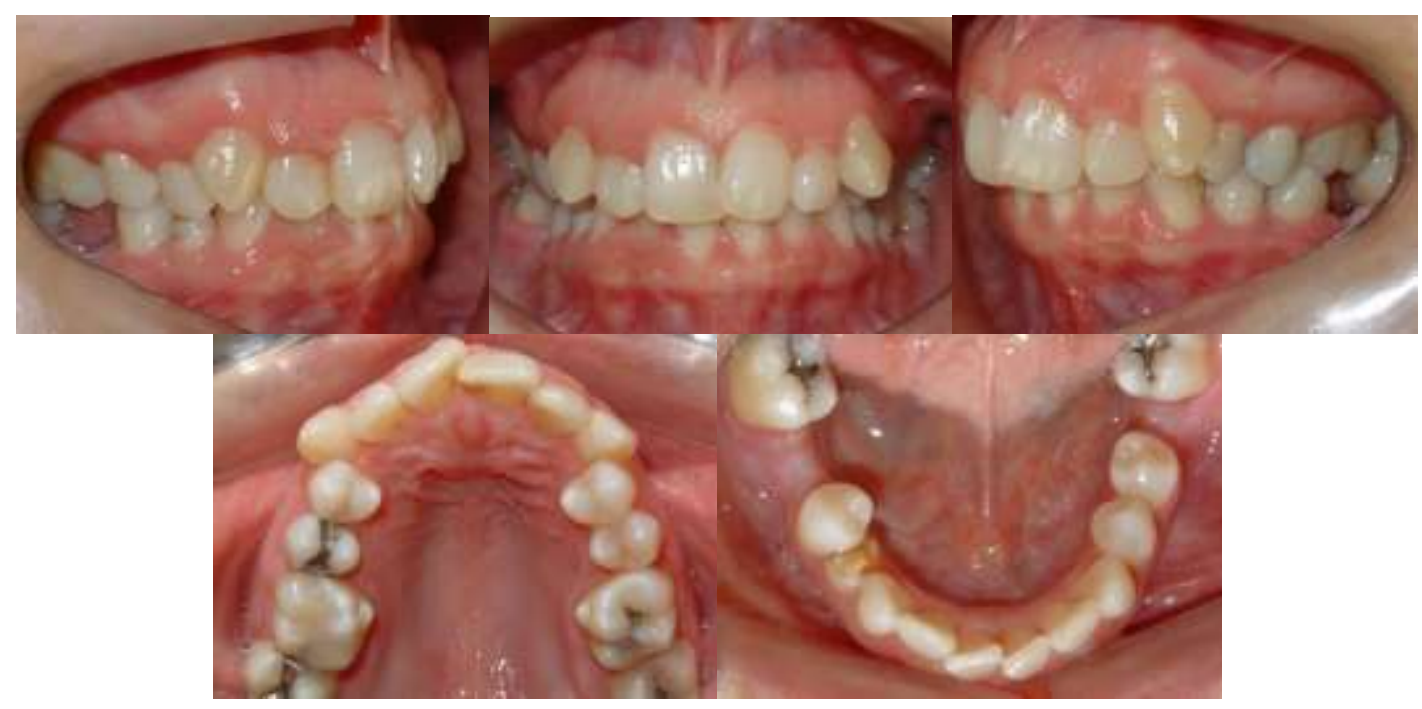

Fonte: Autores.

A análise radiográfica através de radiografia panorâmica inicial demonstrou terceiros molares presentes e inclusos, ausência dos primeiros molares inferiores, segundos molares inferiores angulados para a mesial, presença de destruição coronária do primeiro pré-molar inferior direito (Figura 3). Através da telerradiografia verificou-se inclinação dos incisivos superiores verticalizados em suas bases ósseas (Figura 4). 
Figura 3 - Radiografia panorâmica inicial.

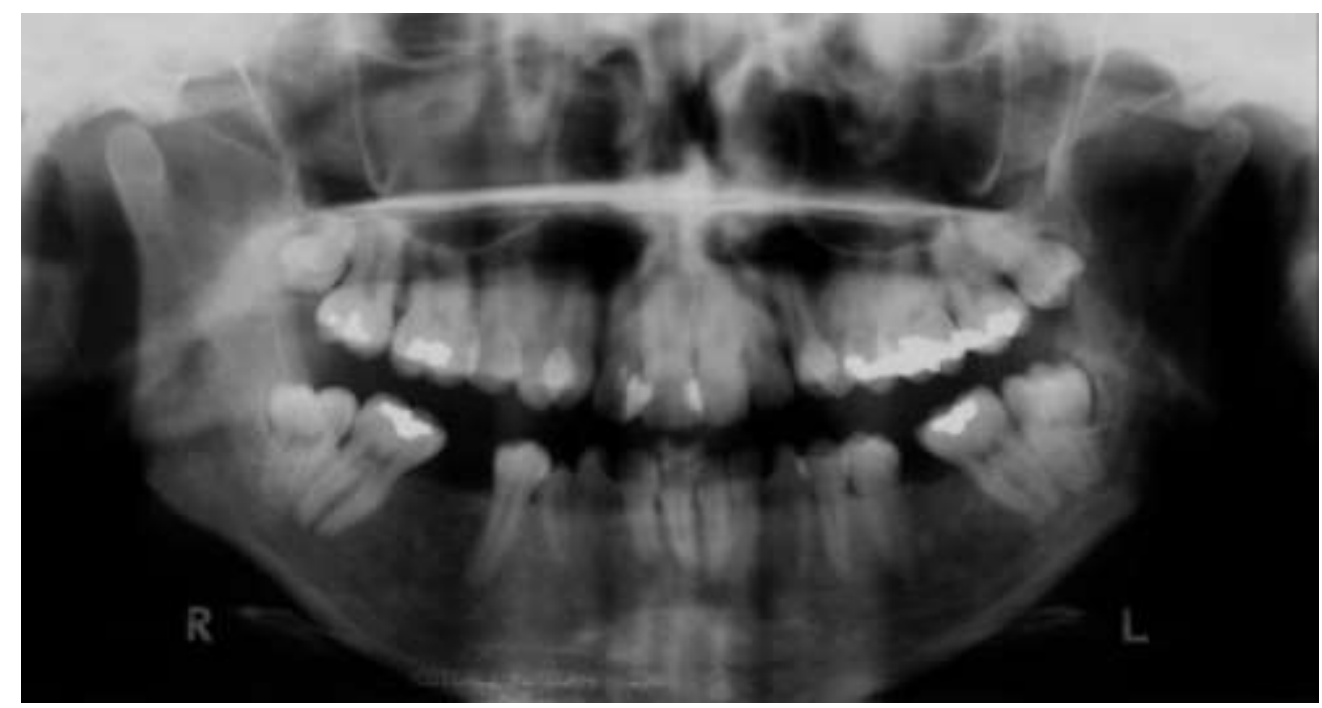

Fonte: Autores.

Figura 4 - Telerradiografia em norma lateral inicial.

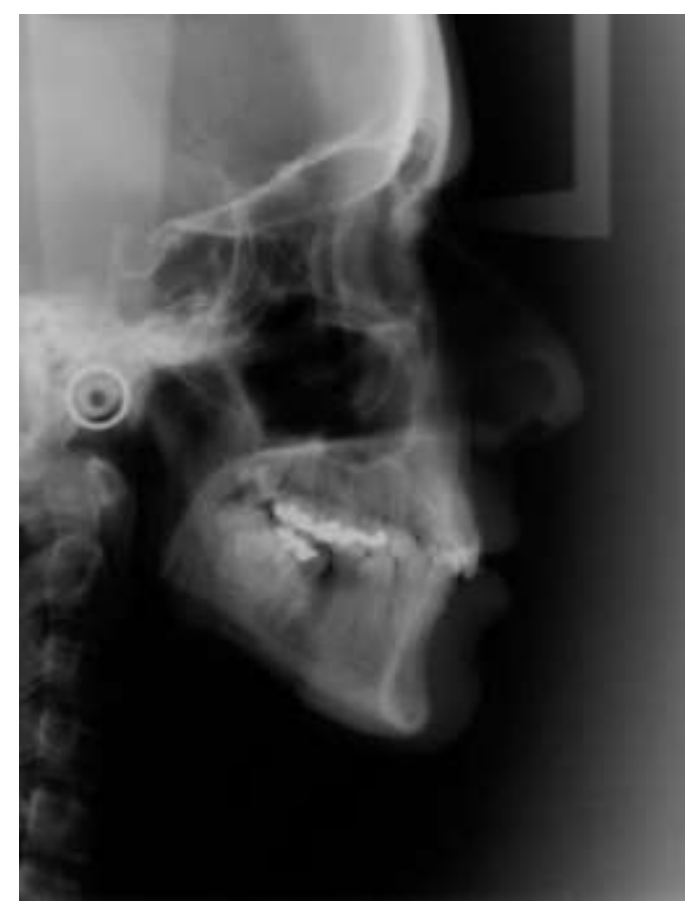

Fonte: Autores.

\section{Alternativas de tratamento}

Foi diagnosticada no caso, a necessidade de extrações dos dentes 14 (primeiro pré-molar superior direito) e 24 (primeiro pré-molar superior esquerdo) para a correção da discrepância anteroposterior e do apinhamento no arco superior. No arco inferior seria possível realizar a reabilitação por meio de implantes e próteses, porém a paciente preferiu a instalação de mini-implantes com o objetivo de mesialização dos molares e fechamento ortodôntico dos espaços edêntulos, com a possibilidade de irrompimento espontâneo dos terceiros molares inferiores. 


\section{Evolução do Tratamento}

O tratamento foi iniciado com as extrações dos dentes 14 e 24 para a correção da discrepância anteroposterior. Foi realizada a instalação dos bráquetes pré-ajustados, ranhura 0,022 ”x0,028”, prescrição Roth. A movimentação dentária iniciouse com a retração dos caninos superiores através de fio 0,014 NiTi, obtendo espaço e o correto alinhamento dos incisivos superiores. Na sequência foram inseridos fios 0,016 " NiTi, 0.018" NiTi, evoluindo-se, deste modo, o alinhamento e nivelamento dos arcos dentários. O fio 0.020 " de aço com curva acentuada no arco superior planificou a curva de Spee e permitiu a colagem dos acessórios no arco inferior (Figura 5).

Figura 5 - Fotos intrabucais da mecânica de alinhamento e nivelamento.

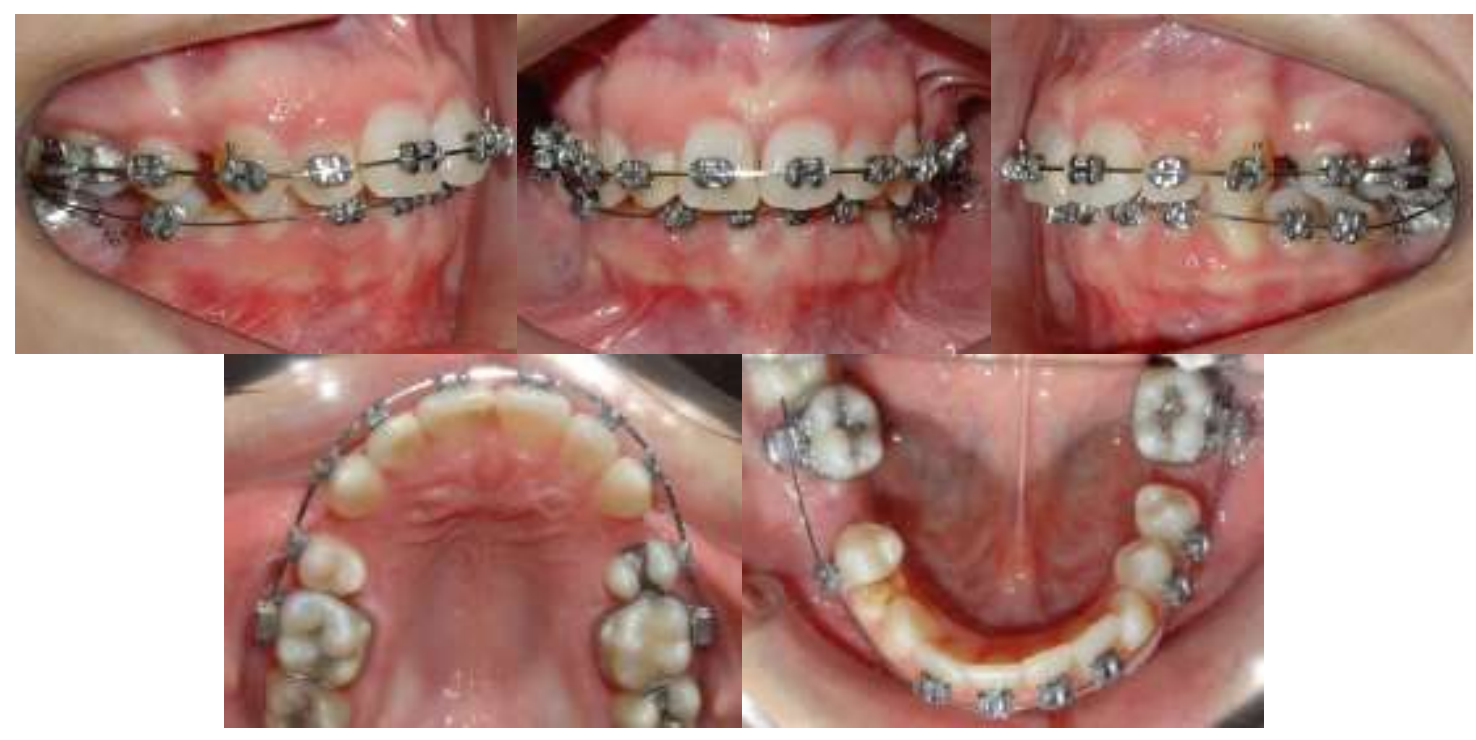

Fonte: Autores.

Ao final do alinhamento, foram inseridos fios retangulares de aço 0,016 "x0,022" no arco superior. Ao mesmo tempo ocorreu a utilização de elásticos corrente com a finalidade de fechamento dos espaços existentes. No arco inferior, instalou-se mola aberta de NiTi na região do primeiro pré-molar inferior direito com o objetivo de ampliar o espaço para futura reabilitação da coroa deste dente (Figura 6). 
Figura 6 - Fechametno dos espaços no arco superior e inserção de mola aberta para reabilitação da coroa do primeiro prémolar inferior direito.

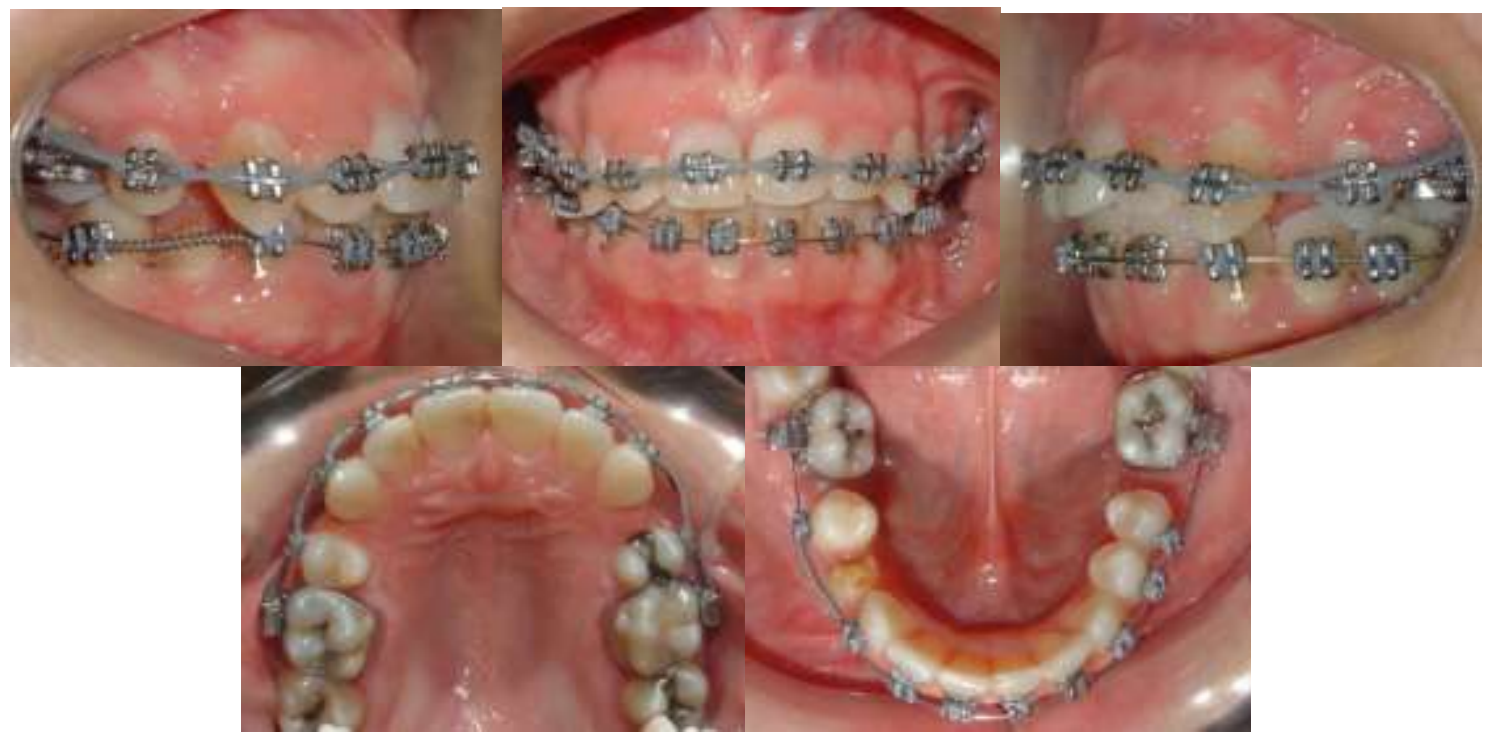

Fonte: Autores.

Após devido posicionamento dentário foram instalados dois mini-implantes da marca SIN de 8mm de comprimento, $1,6 \mathrm{~mm}$ de diâmetro e transmicoso de $1 \mathrm{~mm}$. Um mini-implante foi posicionado na região vestibular distal do dente 35 (segundo pré-molar inferior esquerdo) e o outro na região vestibular distal do dente 45 (segundo pré-molar inferior direito), com finalidade de mesialização por meio do uso dos elásticos em cadeia inseridos no tubo dos segundos molares até os miniimplantes. Foram utilizados elásticos intermaxilares (3/16" de força média) para correção da Classe II do lado esquerdo e a paciente realizou a reabilitação coronária do dente 44 (Figura 7).

Figura 7 - Mecânica de mesialização dos molares inferiores com mini-implante e utilização de elástico intermaxilar 3/16" do lado esquerdo.

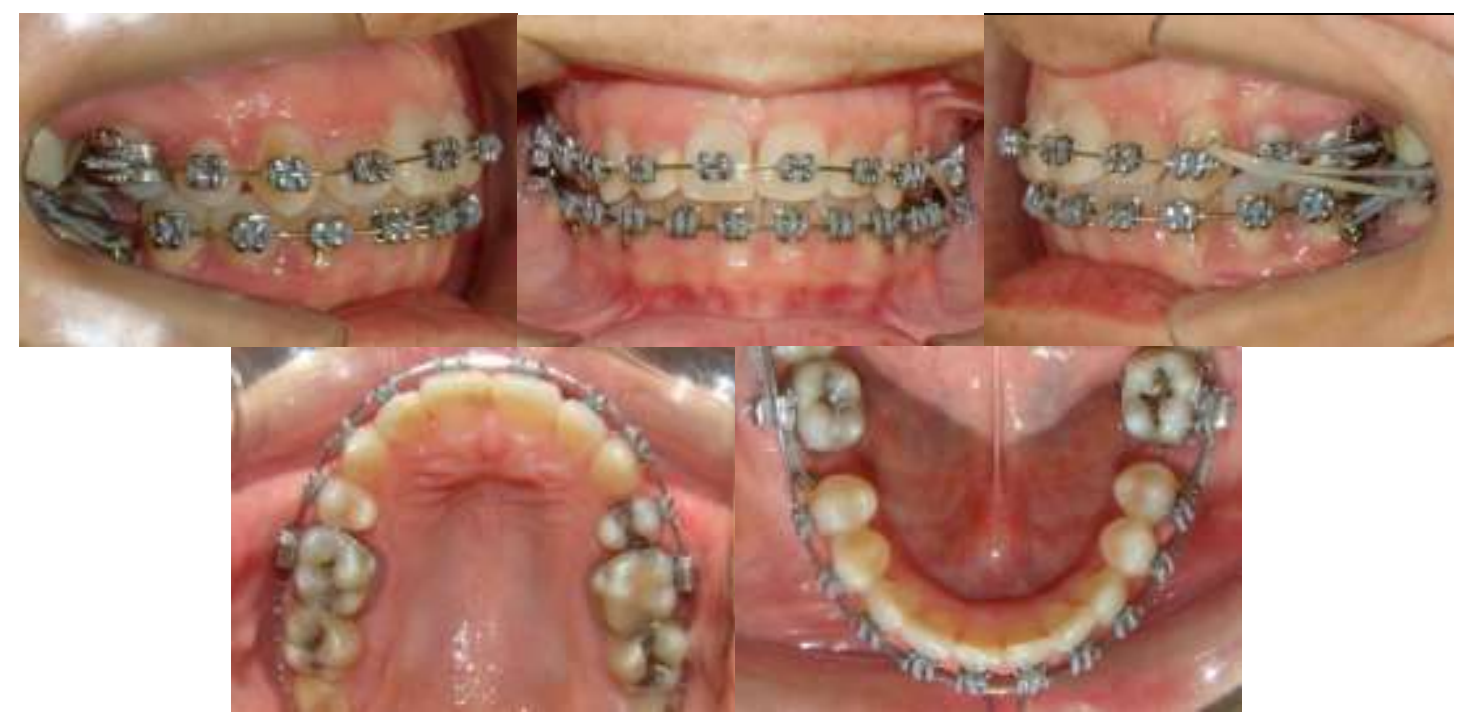

Fonte: Autores.

Durante a mecânica e ao final do movimento de mesialização dos molares inferiores, realizou-se a reversão da curva de Spee em fio contínuo no arco inferior com a finalidade de se controlar a sobremordida (Figura 8). 
Research, Society and Development, v. 10, n. 10, e254101017748, 2021

(CC BY 4.0) | ISSN 2525-3409 | DOI: http://dx.doi.org/10.33448/rsd-v10i10.17748

Figura 8 - Final do fechamento dos espaços dos molares inferiores.

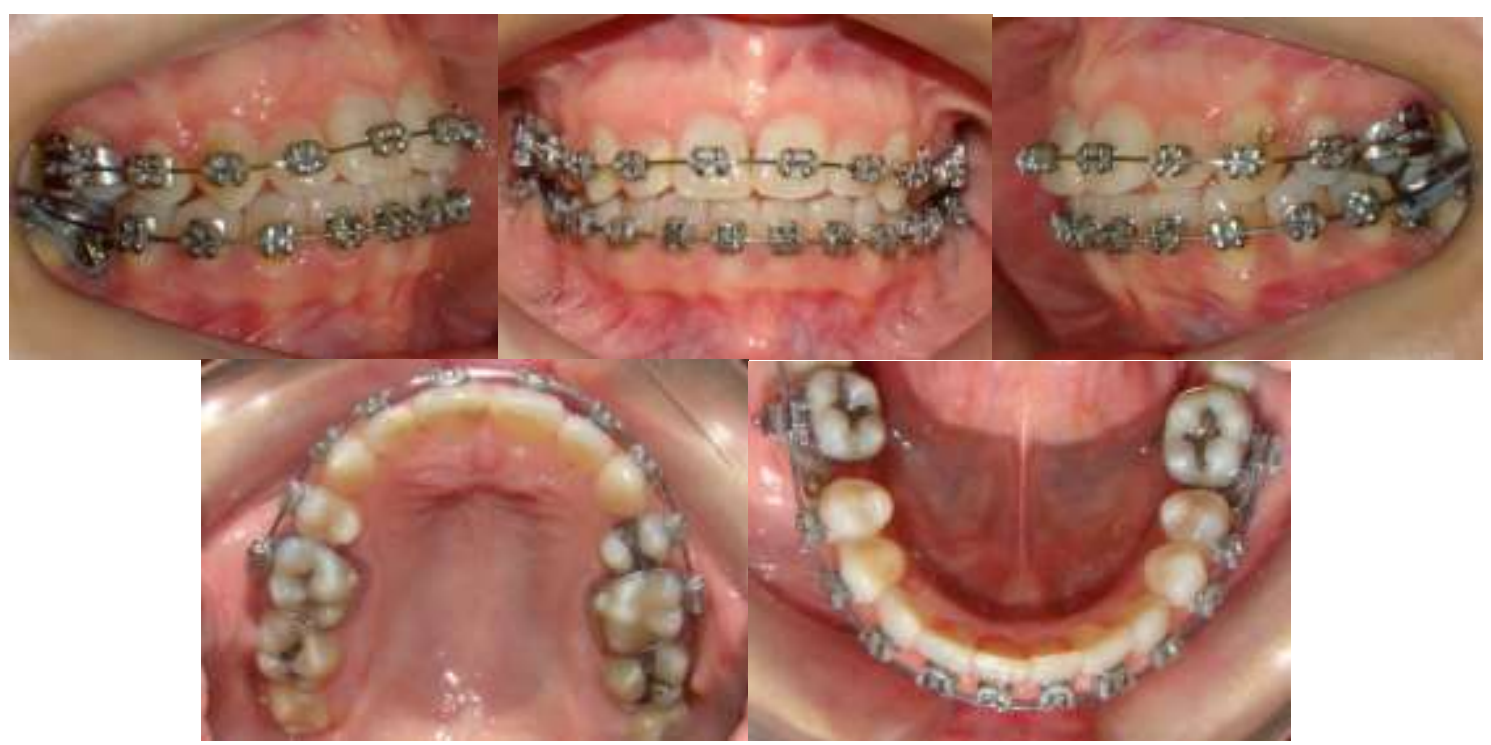

Fonte: Autores.

A remoção dos mini-implantes ocorreu quando os segundos molares inferiores se posicionaram próximos aos segundos pré-molares inferiores. Os tubos dos segundos molares inferiores foram então reposicionados, assim melhorando o posicionamento dentário. Realizou-se a inserção de tubos nos terceiros molares que haviam irrompido espontaneamente no arco dentário (Figura 9).

Figura 9 - Inclusão dos terceiros molares inferiores na mecânica ortodôntica.

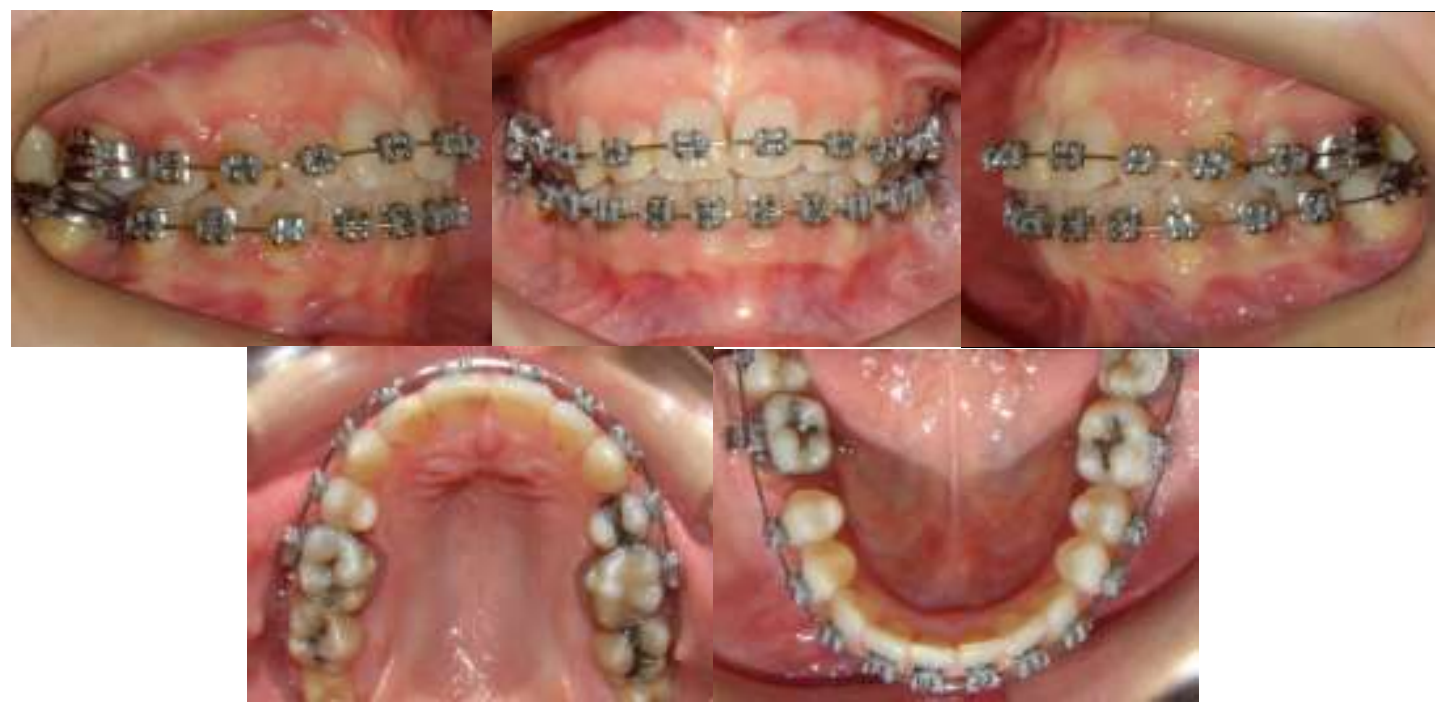

Fonte: Autores.

No arco inferior utilizou-se elástico corrente em todos os dentes para que ocorresse fechamento total dos espaços. No arco superior foram realizadas dobras de finalização para refinamento do tratamento (Figura 10). 
Figura 10 - Elástico Corrente total inferior.

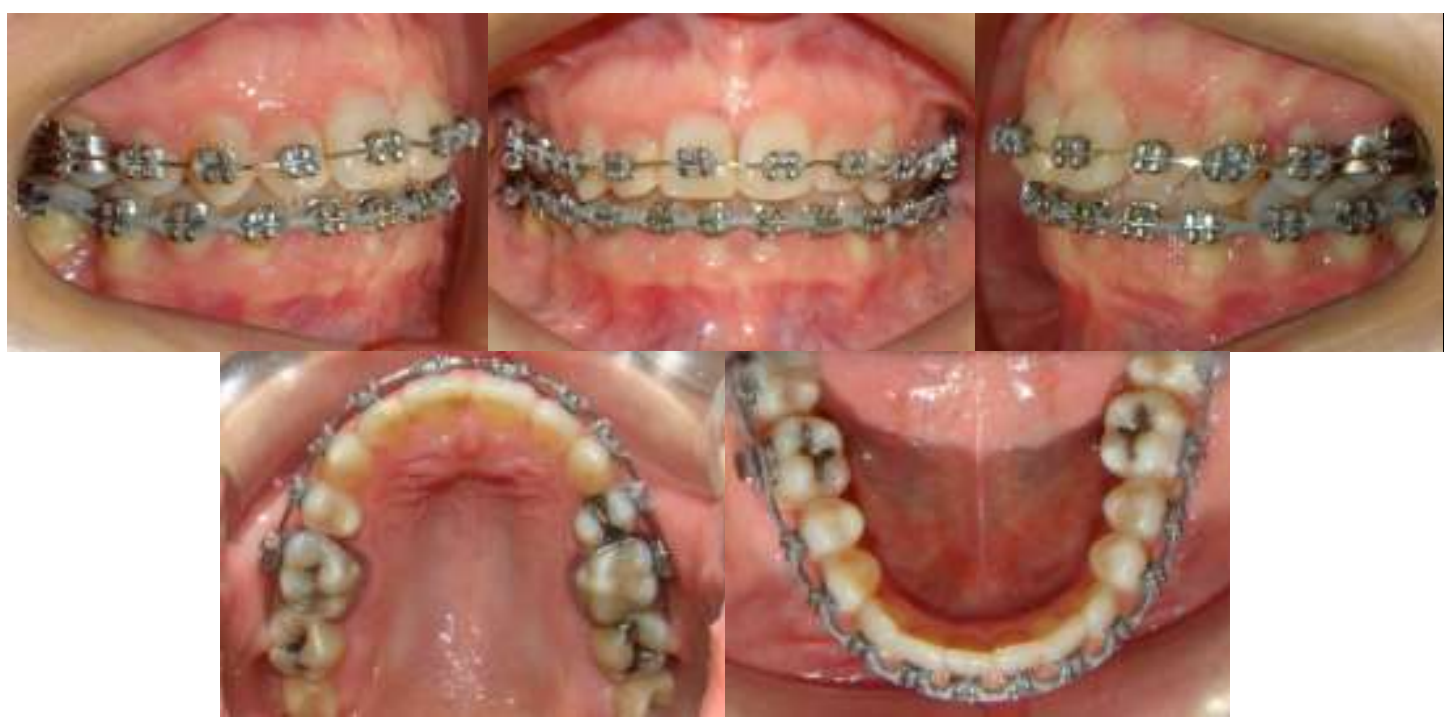

Fonte: Autores.

Após correto posicionamento dentário ocorreu a remoção do aparelho fixo. Neste mesmo momento foi instalada contenção de Hawley superior e contenção 3x3 fixa inferior. A paciente foi encaminhada para tratamento da lesão de cárie do dente 35 (segundo pré-molar inferior esquerdo).

Foi verificado o alinhamento e nivelamento dos dentes, normalização da oclusão, mesialização dos segundos e terceiros molares inferiores resultando no fechamento dos espaços presentes no início do tratamento, restabelecendo a função e estética dentária (Figura 11) sem alterações significativas no perfil facial da paciente (Figura 12).

Figura 11 - Fotos intrabucais. Finalização do tratamento ortodôntico.

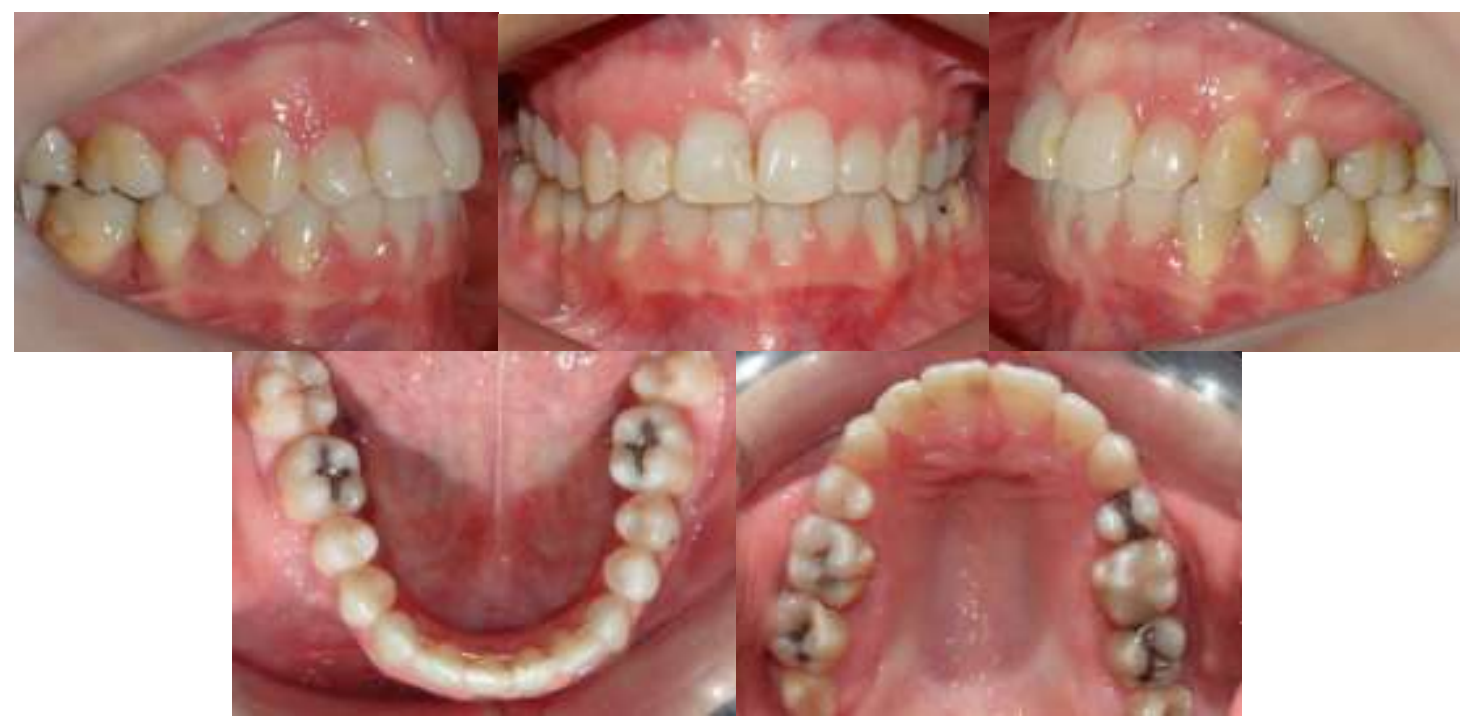

Fonte: Autores. 
Figura 12 - Fotos extrabucais ao término do tratamento.

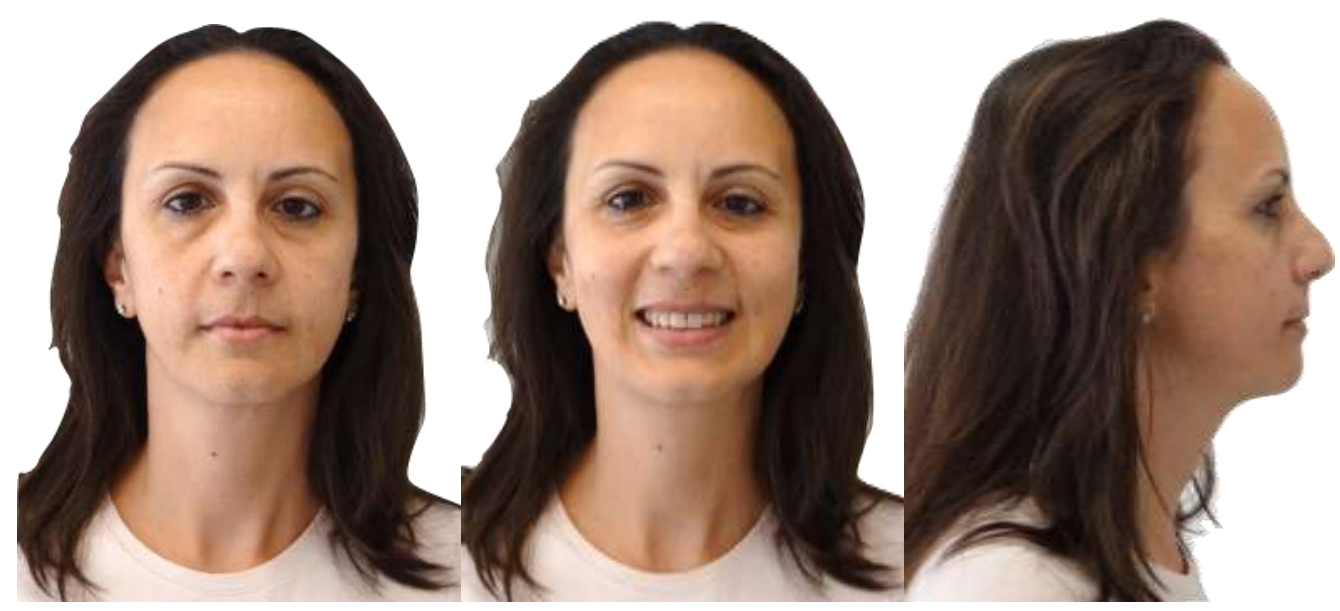

Fonte: Autores.

Por meio da análise final das radiografias (Figuras 13 e 14) é possível verificar correta posição das raízes dos dentes mesializados $(37,38,47,48)$ com presença de leve defeito ósseo vertical na região mesial do dente 37 e 47 . Entretanto, clinicamente, o periodonto de sustentação apresentou-se satisfatório a sondagem com presença de pequena bolsa periodontal.

Figura 13 - Radiografia panorâmica final.

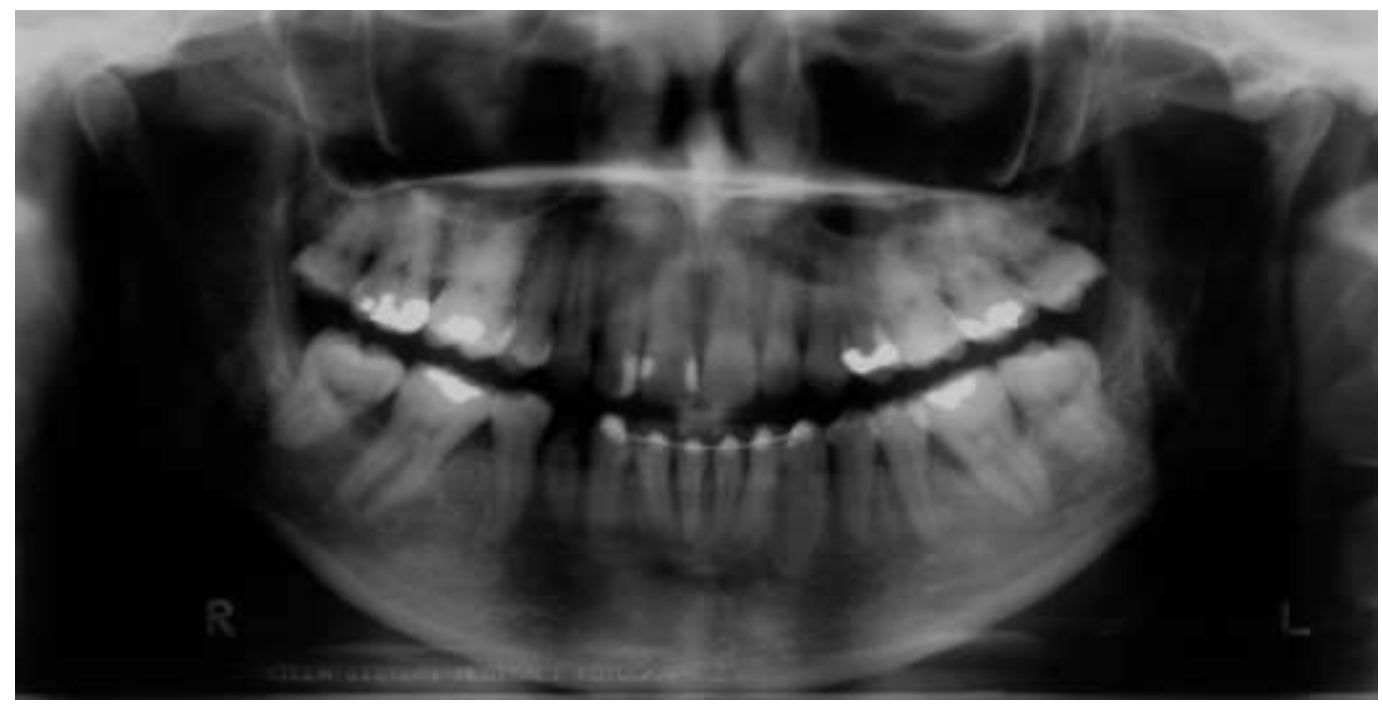

Fonte: Autores. 
Figura 14 - Telerradiografia em norma lateral final.

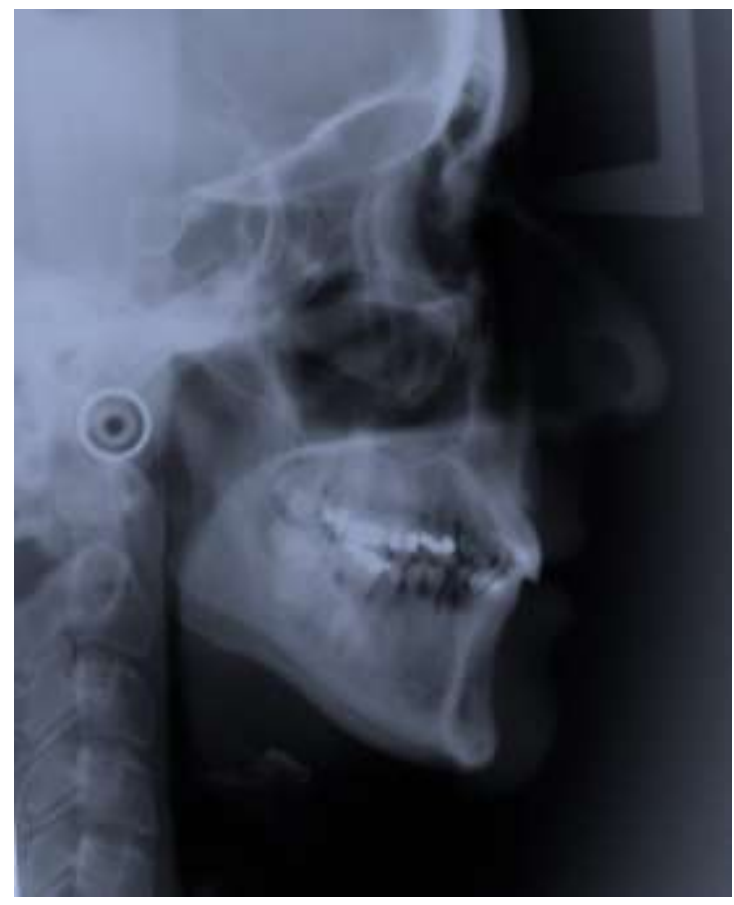

Fonte: Autores.

\section{Resultados}

Foram realizados os traçados cefalométricos do inicio e final do tratamento ortodôntico (Tabela 1). Os mesmos foram sobrepostos com o objetivo de facilitar a visualização das alterações ocorridas no tratamento por meio do programa Dolphin Imaging 10.0 (Figura 15). 
Tabela 1 - Valores cefalométricos iniciais e finais.

\begin{tabular}{|c|c|c|}
\hline \multicolumn{3}{|c|}{ Componente Maxilar } \\
\hline SNA $\left({ }^{\circ}\right)$ & 81,8 & 81,6 \\
\hline Co-A (mm) & 81,3 & 81,1 \\
\hline \multicolumn{3}{|c|}{ Componente Mandibular } \\
\hline SNB $\left(^{\circ}\right)$ & 75,7 & 76,5 \\
\hline Co-Gn (mm) & 111,7 & 112,1 \\
\hline \multicolumn{3}{|c|}{ Relação Maxilomandibular } \\
\hline ANB $\left(^{\circ}\right)$ & 6,1 & 5,3 \\
\hline Wits (mm) & $-0,9$ & $-1,4$ \\
\hline \multicolumn{3}{|c|}{ Componente Vertical } \\
\hline FMA $\left(^{\circ}\right)$ & 32,8 & 32,5 \\
\hline SN.GoGn $\left({ }^{\circ}\right)$ & 39,1 & 39,8 \\
\hline AFAI (mm) & 70,8 & 71,2 \\
\hline \multicolumn{3}{|c|}{ Componente dentoalveolar superior } \\
\hline IS.NA $\left(^{\circ}\right)$ & 11,1 & 17,5 \\
\hline IS-NA (mm) & 0,1 & 1,0 \\
\hline IS-PP (mm) & 32,3 & 31,1 \\
\hline MS-PTV (mm) & 9,0 & 11,8 \\
\hline MS-PP (mm) & 15,4 & 15,8 \\
\hline MS.SN $\left({ }^{\circ}\right)$ & 57,9 & 66,0 \\
\hline \multicolumn{3}{|c|}{ Componente dentoalveolar inferior } \\
\hline II.NB $\left(^{\circ}\right)$ & 24,5 & 25,3 \\
\hline II-NB (mm) & 5,7 & 6,1 \\
\hline II-GoMe (mm) & 40,9 & 40,5 \\
\hline 2MIcoroa-sinfise (mm) & 26,3 & 19,2 \\
\hline 2MI-GoMe (mm) & 20,4 & 22,0 \\
\hline 2MI.GoMe (ㅇ) & 82,2 & 70,0 \\
\hline \multicolumn{3}{|c|}{ Relações Dentárias } \\
\hline Sobressaliência $(\mathrm{mm})$ & 4,9 & 3,5 \\
\hline Sobremordida (mm) & 5,3 & 3,1 \\
\hline \multicolumn{3}{|c|}{ Perfil } \\
\hline Ângulo Nasolabial $\left({ }^{\circ}\right)$ & 122,4 & 123,6 \\
\hline Ls-Linha H (mm) & 2,2 & 0,4 \\
\hline Li-Linha H (mm) & 4,5 & 2,0 \\
\hline
\end{tabular}

Fonte: Autores. 
Figura 15 - Sobreposição dos traçados cefalométricos inicial (preto) e final (verde) na base do crânio (SN) centrado em S. Maxila - sobreposição em plano palatino ( PP) centrado em ENA. Mandibula- sobreposição em plano mandibular (GoMe) centrado em Me.
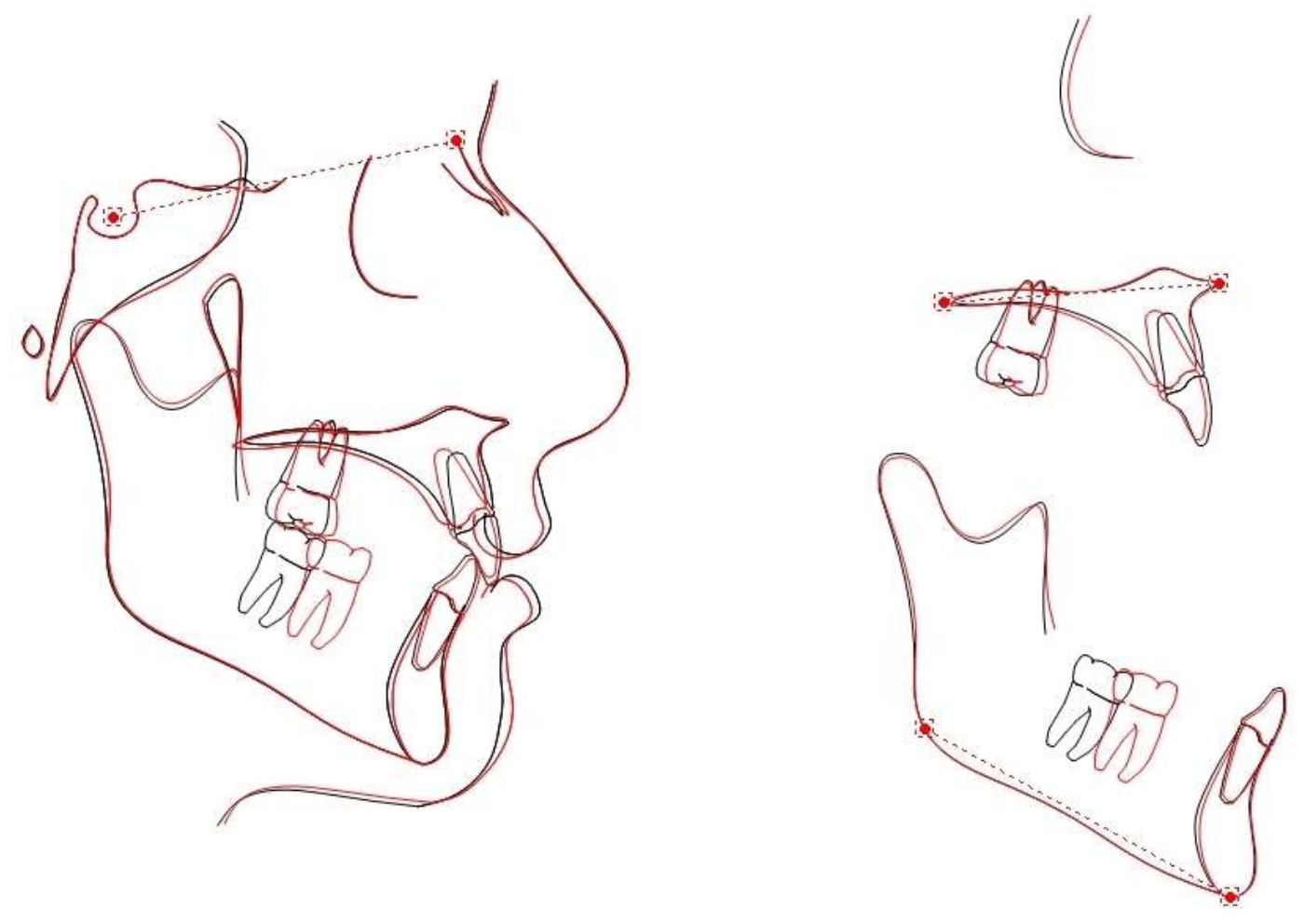

Fonte: Autores.

Ao final do tratamento não foi verificada alterações significantes nos componentes esqueléticos (Tabela 1) (Figura $15)$.

No componente dentoalveolar superior, os incisivos apresentaram vestibularização de $6,4^{\circ}$ com suave protrusão e intrusão. Os molares apresentaram mesialização de $2,8 \mathrm{~mm}$ com angulação mesial de $8,1^{\circ}$.

No componente dentoalveolar inferior, os incisivos não apresentaram alterações significantes. Os molares infeirores mostraram 7,1mm de mesialização com angulação distal de $12,2^{\circ}$ e extrusão de $1,6 \mathrm{~mm}$.

Houve melhora nas relações dentárias com diminuição da sobressliência $(1,4 \mathrm{~mm})$ e sobremordida $(2,2 \mathrm{~mm})$. Não houve alterações significantes no ângulo nasolabial com pequena retração dos lábios superior e inferior.

Ao controle de 1 ano após a finalização do tratamento, a paciente apresentou boa estabilidade oclusal e tecidos periodontais saudáveis (Figura 16). 
Figura 16 - Análise intrabucal após o tratamento ortodôntico.

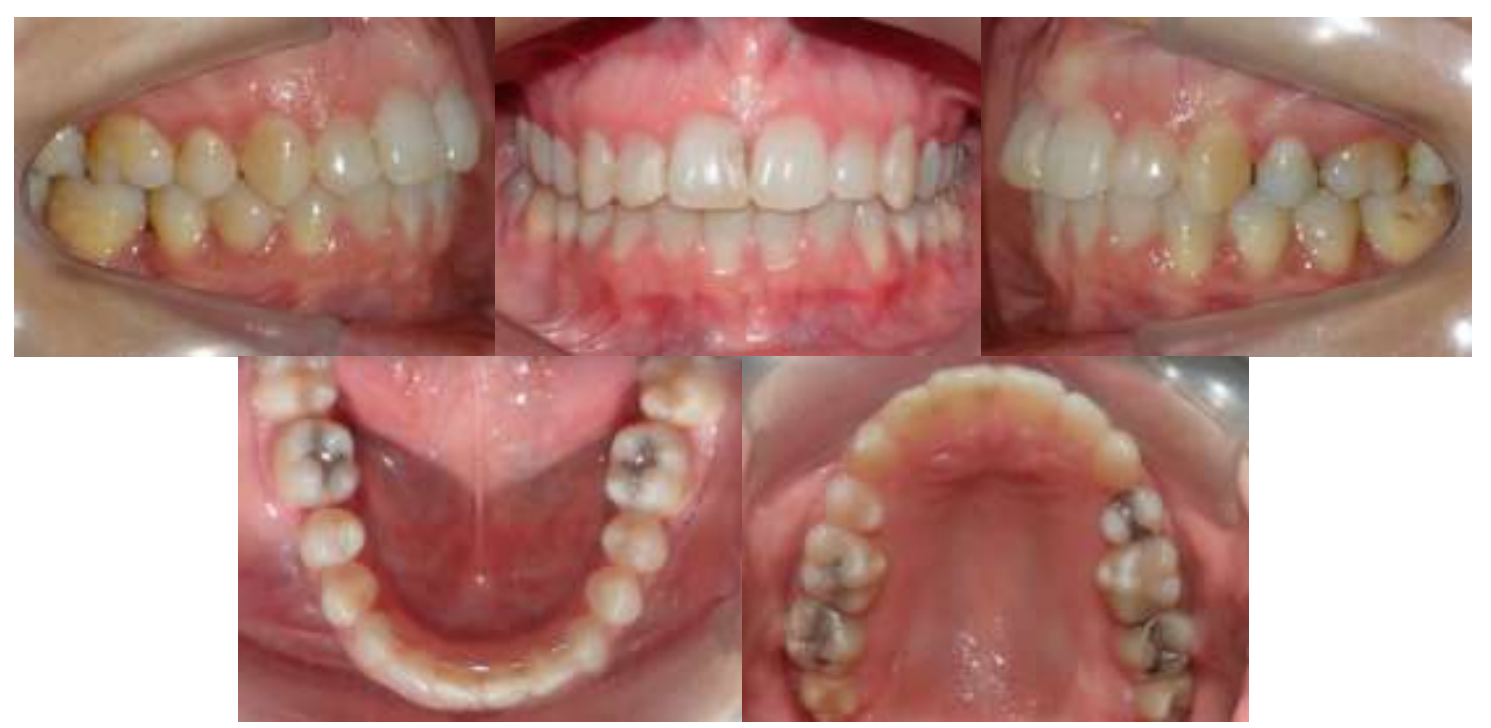

Fonte: Autores.

\section{Discussão}

No caso clínico relatado, a paciente apresentava má oclusão de Classe II dentária e apinhamentos superiores, de forma que para sua correção, optou-se pelas extrações dos dentes 14 (primeiro pré-molar superior direito) e 24 (primeiro pré-molar superior esquerdo). Quando a discrepância anteroposterior está toda contida no apinhamento anterior, a melhor saida está em tratarmos o paciente com duas extrações de pré-molares, pois havera menor influencia nos tecidos moles e assim menores mudanças no perfil facial (Janson, Mendes, Junqueira, \& Garib, 2016; Seben et al., 2013).

Os espaços inferiores das perdas dos primeiros molares foram corrigidos por meio da mesialização dos segundos molares utilizando-se mini-implantes como ancoragem. Dessa forma, evitou-se retração dos dentes anteriores, mantendo a harmonia facial da paciente e não necessitando de procedimentos cirúrgicos complexos ou reabilitações protéticas na região (Baik, 2014; Kyung, Choi, \& Park, 2003).

Entretanto, nem todos os pacientes são passíveis desta movimentação. No paciente adulto, grandes movimentações, seja para distalizar ou para mesializar molares inferiores devem ter grande controle da mecânica ortodôntica empregada (Valarelli et al., 2017). Para a realização dessa abordagem terapêutica é necessária uma análise criteriosa dos dentes a serem mesializados, avaliando a condição periodontal, condição de tecido ósseo alveolar no espaço dos dentes ausentes, tamanho do espaço a ser fechado, presença e posição do terceiro molar, extrusão do antagonista e qualidade óssea em altura e espessura (Carano et al., 2004; Keles, Erverdi, \& Sezen, 2003).

Os vetores de força realizados nos mini-implantes devem ser próximos ao centro de resistência do dente a ser movimentado, possibilitando movimento de corpo e favorecendo a mecânica ortodôntica no fechamento dos espaços, minimizando desta maneira reabsorções radiculares e causando mínimos efeitos colaterais (Carano et al., 2004; Marassi, 2005). Baik, Chun, Jung, e Sugawara, em 2012, mostraram grande dificuldade na mesialização de segundos e terceiros molares em casos de mordida aberta anterior e de grandes espaços das perdas dos primeiros molares. Nagaraj, Upadhyay, e Yadav, em 2008 reportaram diminuição do comprimento das raizes dos segundos molares inferiores quando mesializados mais de $8 \mathrm{~mm}$ para espaços dos primeiros molares.

No caso relatado não foi possível realizar a força de mesialização próxima do centro de resistência dos segundos molares inferiores por causa da pequena profundidade do fundo de vestíbulo, o que impossibilitava a instalação de um cantilever. Mesmo com essa desvantagem, foram realizadas forças de pequena magnitude, controlando-se a angulação dos 
segundos molares que estavam sofrendo o movimento de mesialização. O molar inferior teve um movimento de 7,1 $\mathrm{mm}$ verificado pela variável 2MIcoroa-sínfise (Tabela 1) e não foram notadas diminuições nos comprimentos das raizes.

Geralmente, durante a mecânica de mesialização de molares em grandes espaços há movimento de vestibularização desses dentes (Kravitz \& Jolley, 2008). Esse efeito colateral pode ser evitado, ou ao menos, minimizado, inserindo-se um cantilever com longo braço no sentido vertical, ou inserindo-se torque lingual resistente no fio ortodôntico nessa região (Baik, 2014). Outro efeito colateral observado na mesialização de molares é a vestibularização dos incisivos que ocorre por causa do atrito gerado entre o fio ortodôntico e os tubos dos molares. Esse efeito pode ser minimizado ou evitado por meio da inserção de elásticos em cadeia no arco que está sofrendo a mecânica de mesialização dos molares (Valarelli et al., 2020).

Os mini-implantes foram importantes para que a bateria anterior não se movimentasse para a distal, o que não era desejado nesse caso, já que a paciente apresentava um bom perfil facial (Melsen, 2005; Park et al., 2006).

Consequentemente à movimentação dentária do segundo molar, o terceiro molar também mesializou, devido a ação das fibras supracristais (Gregoret, 2009). Com a mesialização foi possível realizar a colagem do tubo acessório incluindo na mecânica, facilitando assim o fechamento dos espaços remanescentes. É imprescindível a presença do terceiro molar na arco dentário e em posição adequada para que haja sua movimentação (Roberts et al., 1990).

A mesialização de molares inferiores através de mini-implantes não é um protocolo simples de ser realizado, pois a movimentação deve ser feita com forças eficientes e que não causem danos ao dente e ao periodonto adjacente (Keles et al., 2003; Roberts, Arbuckle, \& Analoui, 1996). A taxa de movimentação é de aproximadamente 0,5mm por mês, dessa forma deve-se prever um prazo de tratamento aumentado em relação aos casos convencionais (Janson \& Silva, 2008). Vale ressaltar que em regiões em que o osso alveolar foi perdido há tempos, ele se encontra atrésico e corticalizado e tende ser mais resistente ao movimento e consequentemente ao tratamento (Kokich, 2006) (Henneman, Von den Hoff, \& Maltha, 2008). Neste trabalho a paciente estava em fase adulta, o que resultou maior tempo de tratamento até a mesialização total dos molares inferiores e o completo fechamento dos espaços.

Quando ocorre a mesialisação dos molares inferiores, como consequência surgem formações de pseudobolsas ou bolsas periodontais verdadeiras na mesial do dente angulado (Janson, Janson, \& Martins, 2001). Essas alterações ocorrem devido à tendência da crista óssea alveolar em acompanhar a junção cemento-esmalte, aliada a dificuldade de higienização nessa mesma área (Di Matteo RC, 2005). Clinicamente, no paciente deste trabalho, o periodonto não apresentou sequelas durante o processo de mesialização .

Ao final do tratamento da paciente em questão, o resultado foi satisfatório com mínimos efeitos colaterais ao perfil facial. Situações como esta são rotineiras no consultório odontológico e pacientes com ausência de molares inferiores, costumam se mostrar mais aptos ao fechamento dos espaços de forma ortodôntica (Kim, Sung, Kim, Baik, \& Lee, 2015). O ortodontista deve avaliar corretamente as condições do tratamento e realizar um preciso diagnóstico do problema do paciente para indicar a melhor terapia a ser utilizada, eventualmente combinando terapias com extrações dentárias e ancoragem absoluta para a correção das discrepâncias existentes.

\section{Conclusão}

Por meio do caso clínico apresentado nesse trabalho verifica-se que é possível realizar o fechamento dos espaços de perdas dentárias inferiores por meio da mesialização dos molares inferiores sem alterar significativamente o perfil da paciente e os tecidos periodontais. 


\section{Referências}

Araújo, T. M., Nascimento, M. H. A., Bezerra, F., \& Sobral, M. C. (2006). Ancoragem esquelética em Ortodontia com miniimplantes. Revista Dental Press de Ortodontia e Ortopedia Facial, 11(4), 126-156.

Baik, U.-B., Chun, Y.-S., Jung, M.-H., \& Sugawara, J. (2012). Protraction of mandibular second and third molars into missing first molar spaces for a patient with an anterior open bite and anterior spacing. American Journal of Orthodontics and Dentofacial Orthopedics, 141(6), 783-795.

Baik, U. B. (2014). Molar Protraction: Orthodontic substitution of missing posterior teeth. In Temporary Skeletal Anchorage Devices (pp. 119-160): Springer.

Carano, A., Velo, S., Incorvati, C., \& Poggio, P. (2004). Clinical applications of the Mini-Screw-Anchorage-System (M.A.S.) in the maxillary alveolar bone. Progress in Orthodontics, 5(2), 212-235.

Di Matteo RC, V. N. S. W. (2005). Movimentação de Molares Inferiores Ancorados em Miniparafusos. Revista Dental Press de Ortodontia e Ortopedia Facial, 10(4), 124-133.

Gregoret, G. (2009). Biomecánica de mesialización inferior con micro-implantes. Gaceta Dental, 201, 112-129.

Henneman, S., Von den Hoff, J. W., \& Maltha, J. C. (2008). Mechanobiology of tooth movement. European Journal of Orthodontics, 30(3), 299-306. doi: $10.1093 /$ ejo/cjn020

Janson, G., Mendes, L. M., Junqueira, C. H., \& Garib, D. G. (2016). Soft-tissue changes in Class II malocclusion patients treated with extractions: a systematic review. European Journal of Orthodontics, 38(6), 631-637. 10.1093/ejo/cjv083

Janson, M., \& Silva, D. F. A. (2008). Mesialização de Molares com Ancoragem em Mini-implantes. Revista Dental Press de Ortodontia e Ortopedia Facial, $13,88-94$.

Janson, M. R. P., Janson, R. R. P., \& Martins, P. F. (2001). Tratamento Interdiciplinar I: Considerações Clínicas e Biológicas na Verticalização de Molares. Revista Dental Press de Ortodontia e Ortopedia Facial, 6(3), 87-104.

Keles, A., Erverdi, N., \& Sezen, S. (2003). Bodily distalization of molars with absolute anchorage. Angle Orthodontist, 73(4), 471-482. doi:10.1043/00033219(2003)073<0471:BDOMWA $>2.0 . \mathrm{CO} ; 2$

Kim, S. J., Sung, E. H., Kim, J. W., Baik, H. S., \& Lee, K. J. (2015). Mandibular molar protraction as an alternative treatment for edentulous spaces: Focus on changes in root length and alveolar bone height. Journal of the American Dental Association, 146(11), 820-829. doi:10.1016/j.adaj.2015.04.025

Kokich, V. G. (2006). Entrevista Dr. Vicente G. Kokich. Revista Dental Press de Ortodontia e Ortopedia Facial, 11(6), 19-23.

Kravitz, N. D., \& Jolley, T. (2008). Mandibular molar protraction with temporary anchorage devices. Journal of Clinical Orthodontics, 42(6), 351.

Kyung, S.-H., Choi, J.-H., \& Park, Y.-C. (2003). Miniscrew anchorage used to protract lower second molars into first molar extraction sites. Journal of Clinical Orthodontics, 37(10), 575-579.

Marassi, C. E. A. (2005). O uso de miniimplantes como auxiliares do tratamento ortodôntico. Ortodontia SPO, 38( 3), $256-265$.

Melsen, B. (2005). Mini-implants: Where are we? Journal of Clinical Orthodontics, 39(9), 539-547; quiz 531-532.

Nagaraj, K., Upadhyay, M., \& Yadav, S. (2008). Titanium screw anchorage for protraction of mandibular second molars into first molar extraction sites. American Journal of Orthodontics and Dentofacial Orthopedics, 134(4), 583-591.

Park, H. S., Jeong, S. H., \& Kwon, O. W. (2006). Factors affecting the clinical success of screw implants used as orthodontic anchorage. American Journal of Orthodontics and Dentofacial Orthopedics, 130(1), 18-25. doi:10.1016/j.ajodo.2004.11.032

Roberts, W. E., Arbuckle, G. R., \& Analoui, M. (1996). Rate of mesial translation of mandibular molars using implant-anchored mechanics. Angle Orthodontist, 66(5), 331-338. doi:10.1043/0003-3219(1996)066<0331:ROMTOM>2.3.CO;2

Roberts, W. E., Marshall, K. J., \& Mozsary, P. G. (1990). Rigid endosseous implant utilized as anchorage to protract molars and close an atrophic extraction site. Angle Orthodontist, 60(2), 135-152.

Sakima, T., Martins, L. P., Sakima, M. T., Terada, H. H., Kawakami, R. Y., \& Ozawa, T. O. (1999). Alternativas mecânicas na verticalização de molares. Sistemas de forças liberados pelos aparelhos Revista Dental Press de Ortodontia e Ortopedia Facial, 4(1), 79-100.

Seben, M. P. et al. (2013) Cephalometric changes in Class II division 1 patients treated with two maxillary premolars extraction. Dental Press J Orthodontics, 18(4), 61-69.

Valarelli, F. P. et al. (2014) Verticalização e mesialização de molar inferior com ancoragem em mini-implante. Orthoscience Orthodontic Science and Practice, 7(26), 216-224.

Valarelli, F. P. et al. (2017) Lower-molar distalization with mini-implant Anchorage in asymmetrical Class II cases. Journal of Clinical Orthodontics, 51(2), 86-94.

Valarell, F. P. et al. (2020) Treatment of mandibular canine agenesis with boné-anchored protraction of posterior teeth. Journal of Clinical Orthodontics, $54(7), 419-428$. 